\title{
Investigation of Binding Affinity between Potential Antiviral Agents and PB2 Protein of Influenza A: Non-equilibrium Molecular Dynamics Simulation Approach
}

\author{
Tri Pham ${ }^{1,2}$, Hoang Linh Nguyen ${ }^{1,2}$, Tuyn Phan-Toai ${ }^{1}$, and Hung Nguyen ${ }^{1 凶}$ \\ 1. Institute for Computational Science and Technology, Ho Chi Minh City, Vietnam. \\ 2. VNUHCM-University of Technology, Ho Chi Minh City, Vietnam. \\ $\square$ Corresponding author: E-mail: hung.nv@icst.org.vn (H.N).
}

(c) The author(s). This is an open access article distributed under the terms of the Creative Commons Attribution License (https://creativecommons.org/licenses/by/4.0/). See http://ivyspring.com/terms for full terms and conditions.

Received: 2020.03.22; Accepted: 2020.07.09; Published: 2020.07.25

\begin{abstract}
The PB2 protein of the influenza virus RNA polymerase is a major virulence determinant of influenza viruses. It binds to the cap structure at the 5' end of host mRNA to generate short capped RNA fragments that are used as primers for viral transcription named cap-snatching. A large number of the compounds were shown to bind the minimal cap-binding domain of PB2 to inhibit the cap-snatching machinery. However, their binding in the context of an extended form of the PB2 protein has remained elusive. A previous study reported some promising compounds including azaindole and hydroxymethyl azaindole, which were analyzed here to predict binding affinity to PB2 protein using the steered molecular dynamics (SMD) and molecular mechanics Poisson-Boltzmann surface area (MM-PBSA) methods. The results show that the rupture force $\left(F_{\max }\right)$ value of three complexes is in agreement with the binding free energy value $\left(\Delta G_{\text {bind }}\right)$ estimated by the MM-PBSA method, whereas for the non-equilibrium pulling work $\left(W_{\text {pull }}\right)$ value a small difference between $A$ PB2-4 and A PB2-12 was observed. The binding affinity results indicate the A PB2-12 complex is more favorable than the A_PB2-4 and A_PB2-16 complexes, which means the inhibitor $(1 \overline{2})$ has the potential to be further developed as anti-influenza agents in the treatment of influenza $A$.
\end{abstract}

Key words: Azaindole (4 and 16), hydroxymethyl azaindole (12), protein_PB2, SMD, MM-PBSA

\section{Introduction}

Both seasonal and pandemic influenza have been causing severe illness and death for both humans and farm animals [1]. The virus variants have emerged and posed a constant threat to human health. Changes in viral genes often result in viral evolutionary advantages, such as the degree of virulence and the more efficient replication and transmissibility of the virus [2].

There has been four main influenza A pandemics, including the H1N1 Spanish flu (1918), the H2N2 Asian flu (1957), the H3N2 Hong Kong flu (1968), and the H1N1 swine flu (2009) [3,4]. These have been examples of fast transmission of animal influenza viruses to humans [5]. Although vaccination could prevent influenza for $70-90 \%$ of healthy adults
$[6,7]$, it is only effective against a limited range of strains and it practically has no effect against new and potentially pandemic strains [8-10]. Therefore, the development of effective drugs against influenza is currently considered as a high priority by different governmental and international agencies, especially by pharmaceutical industries at the worldwide scale.

The influenza virus is an enveloped virus, in which the outer layer is a lipid membrane, which is taken from the host cell where the virus multiplies $[11,12]$. A glycoprotein is a type of protein molecule linked to sugar. When it is located in a cell membrane, it helps to identify and communicate with the cell. The cell uses the glycoproteins embedded in the plasma membrane to get the oligosaccharides on the outside 
of the cell, which is typically decorated with different oligosaccharides such as hemagglutinin (HA) $[13,14]$ and neuraminidase (NA) [15]. The NA protein is actually the target of the antiviral drugs Relenza and Tamiflu [16,17]. Additionally, the M2 protein is also a membrane protein and is a target of the antiviral Adamantanes (including Amantadine and Rimantadine) $[18,19]$. However, the long-term effectiveness of these drugs is a matter of great concern due to the emergence of drug-resistant strains of the virus. Thus, there is an urgent need for new agents to prevent and treat the influenza virus infection, especially in high-risk groups and during pandemic influenza.

Some previous studies showed that some small molecule inhibitors were able to make novel targets in the influenza life cycle against [20-30]. The genome of the influenza virus includes eight different ribonucleoprotein complexes that enclose eight viral genomic RNA segments. Similarly to other negativestranded RNA viruses, the viral RNA polymerase of influenza virus is always packaged in the infectious virion as a complex with the nucleoprotein [31-34]. The RNA-dependent RNA polymerase of influenza virus is composed of the PA, PB1, and PB2 subunits. A heterotrimeric polymerase is required for RNA transcription and replication that take place in the nucleus during influenza virus infection [33].

The influenza virus is based on a cap-snatching mechanism to accomplish its transcription [35]. Following the entrance of the ribonucleoprotein complexes into the nucleus, the $5^{\prime}$ cap of the host premRNA in the nucleus is captured by the cap-binding domain of PB2 [36]. Together with 10-13 nucleotides downstream, the $5^{\prime}$ cap is subsequently cleaved off by the N-terminal cap-dependent endonuclease of PA [37]. This $5^{\prime}$-capped oligonucleotide is used as the primer for initiation of the viral transcription by PB1 [38]. This process is called as a "cap-snatching" mechanism, which allows the endonuclease to cleave the $5^{\prime}$ caps from host RNAs, and then the latter act as transcription primers [39]. Clearly, the PB2 subunit is linked to the initiation of viral transcription and is known as a cap-binding protein [40-42]. According to recent studies, a cap-primer-dependent in vitro RNA synthesis is affected by the PB2 gene and, therefore, a series of in vitro inhibitors has supported such role for PB2 [43]. monoclonal antibodies specific for the PB2 subunit have interfered with the initiation step of mRNA-primed transcription in vitro [44], and antibodies monospecific for the $\mathrm{C}$ terminus of PB2 have inhibited cap snatching and cap-dependent transcription in vitro but not cap-binding [45]. Moreover, antibodies directed to the region from positions 300 to 550 in PB2 inhibited cap snatching and partially affected cap recognition [46,47].
However, the activities of both transcription and capdependent endonuclease have required the presence of all three subunits of the polymerase and the RNA template $[48,49]$.

To elucidate some crucial molecular determinants for the interaction of some inhibitors with PB2 protein of influenza A (protein_PB2), the binding affinity of the azaindole $(4 \& 16)$ and hydroxymethyl azaindole (12) for PB2 protein was predicted. For this purpose, the different theoretical methods including steered molecular dynamics (SMD) [50-52] and Molecular Mechanics Poisson-Boltzmann Surface Area (MM-PBSA) $[53,54]$ were used to compute the binding affinities of these inhibitors for protein_PB2.

\section{Materials and Method}

\section{Preparing the structures}

The 3D structures of the complexes were taken from Protein Data Bank with PDB ID: 5JUN (A_PB2-4) [55], 5BUH (A_PB2-12) and 5F79 (A_PB2-16) [56]. The 2D structures of the inhibitors (4), (12) and (16) are shown in Figure 1. The inhibitor topologies and coordinate files were generated by using Swiss Param [57].

\section{Molecular dynamics simulations}

\section{Molecular dynamics simulation}

The simulation processes of complexes were conducted by using CHARMM 27 force field [58] implemented in the GROMACS 5.1.2 package [58] at absolute temperature $300 \mathrm{~K}$. The TIP3P water model [60] was used in all simulation systems. All distance bonds within the proteins were constrained by the Linear Constraint Solver (LINCS) algorithm [61]. The electrostatic and van der Waals interactions were used to depict non-bonded interactions, with the non-bonded interaction pair-list being updated every $10 \mathrm{fs}$ using a cutoff of $1.4 \mathrm{~nm}$. The Particle Mesh Ewald truncation method [62] was used to treat the long-range electrostatic interactions. From these structures, short 2 ns MD simulations were performed in the NVT ensemble, which were followed by $3 \mathrm{~ns}$ NPT simulation. The leap-frog algorithm [63] was used to integrate the equations of motion with the time step set to $2 \mathrm{fs}$ for the MD simulations.

\section{Steered molecular dynamics (SMD) simulation}

\section{Choosing a pathway}

Caver 3.0 [64] package was used to determine the pulling pathway through the widest tunnel as this minimizes the occurrence of collisions between the inhibitor and protein_PB2 during the simulation. Then the Caver 3.0 and PyMOL [65] packages were employed to rotate the protein_PB2 in such a way that 
the inhibitor unbinding pathway is along the z-axis (Figure 1).

Preparing Steered Molecular Dynamics (SMD) simulation

In the Steered Molecular Dynamics (SMD) simulation [50-52], each of the inhibitor-protein_PB2 complexes was placed in a triclinic box of $6 \mathrm{~nm} \times 6 \mathrm{~nm}$ $\times 14 \mathrm{~nm}$ to have enough space to pull the inhibitor out of the binding site. The three-dimensional coordinates of the center of the complex were $3 \mathrm{~nm} \times 3 \mathrm{~nm} \times 3 \mathrm{~nm}$. The complexes were immersed in a salt solution with a concentration of $0.15 \mathrm{M}$ of sodium and chloride to neutralize the total charge.

The pulling force is measured according to the following equation:

$$
F(t)=k\left[v t-\left(\vec{r}-\vec{r}_{0}\right) \vec{n}\right]
$$

where $k$ is the force constant, $v$ is the pulling velocity, $\vec{n}$ is the pulling direction normal, $\vec{r}$ and $\vec{r}_{0}$ are the positions of protein at time $t$ and initial time, respectively. During the simulations, the spring constant $k$ value was set to $600 \mathrm{~kJ} /\left(\mathrm{mol}_{\mathrm{nm}}{ }^{2}\right)$ (approximately $1020 \mathrm{pN} / \mathrm{nm}$ ), which is a typical value used in atomic force microscope (AFM) experiments [66]. The complete dissociation of the inhibitor from the binding pocket of protein_PB2 was reached during 500 ps for three complexes with pulling velocity set at $v=0.005 \mathrm{~nm} / \mathrm{ps}$.

In order to calculate the relative binding affinities of the complexes using the SMD simulation, the non-equilibrium pulling work profile was used to evaluate a scoring function to rank the binding affinities between the inhibitor and protein. The non-equilibrium pulling work $W_{\text {pull }}$ is approximately defined as follows:

$$
W_{\text {pull }}=\int F(r) d r=\frac{1}{2} \sum_{i=1}^{n-1}\left(f_{i+1}+f_{i}\right)\left(r_{i+1}-r_{i}\right)
$$

where $W_{\text {pull }}$ is the non-equilibrium pulling work of external force $f$, and $n-1$ is the number of steps in the SMD simulation, $\left(r_{i+1}-r_{i}\right)$ is the inhibitor displacement in step $i$, here the centers of mass (COM) of the inhibitors were employed to measure the inhibitor displacement.

\section{MM-PBSA free energy calculations}

To estimate binding free energy between the inhibitors and protein_PB2, each snapshot extracted from the equilibrium MD simulation was used to estimate the binding free energy using the MM-PBSA method. The binding free energy of the inhibitorprotein is computed by this approach as follows $[53,54]$ :

$$
\Delta G_{\text {bind }}=\Delta E_{\text {elec }}+\Delta E_{v d W}+\Delta G_{\text {sur }}+\Delta G_{P B}-T \Delta S
$$

where $\Delta E_{\text {elec }}$ and $\Delta E_{v d W}$ are contributions of electrostatic and vdW energies, respectively [67]. $\Delta G_{\text {sur }}$ and $\Delta G_{P B}$ are non-polar and polar solvation energies [68]. Here, $\Delta G_{P B}$ derived from the electrostatic potential between solute and solvent was determined using the continuum solvent approximation [69]. It is the change of electrostatic energy from transferring solute in a continuum medium, from a low solute dielectric constant $(\varepsilon=2)$ to a higher one with water without salt $(\varepsilon=78.45)$. Using a grid spacing of $0.1 \AA$, the APBS package [70] was implemented for numerical solution of the corresponding linear Poisson-Boltzmann equation. The nonpolar solvation term $\Delta G_{\text {sur }}$ was approximated as linearly dependent on the solvent accessible surface area (SASA), derived from Shrake-Rupley numerical method [71] integrated in the APBS package. $\Delta G_{\text {sur }}=$ $\gamma \mathrm{SASA}+\beta$, where $\gamma=0.0072 \mathrm{kcal} / \mathrm{mol} . \AA^{2}$ and $\beta=0$ [72]. The entropic contribution $T \Delta S$ is determined using the normal mode approximation [73].

\section{Measures used in data analysis}

The contact networks between the inhibitors and protein_PB2 were determined by using the LigPlot and PyMOL packages $[65,74]$. The root mean square deviation (RMSD), the number of hydrogen bond (H-bond) and the number of contacts (NC) were calculated by the "gmx_mpi hbond" and "gmx_mpi mindist" tools in the GROMACS package. The standard errors of the mean (E) are approximately estimated as follows:

$$
E=\sqrt{\frac{\sum_{i=1}^{N}\left(x_{i}-\langle x\rangle\right)^{2}}{N}}
$$

Where $\mathrm{N}$ is the number of snapshots, $\mathrm{x}_{\mathrm{i}}$ is a quantity at each snapshot, and $\langle x\rangle$ is the average value of $x_{i}$.

\section{Results}

\section{The contact network and stability of the complexes}

In order to indicate the stability of the systems including A_PB2-4, A_PB2-12, and A_PB2-16, the RMSD time profiles calculated for protein_PB2's backbone and the inhibitor's heavy atoms are shown in Figure 2A \& B for every analyzed system. The RMSD values reveal that the three systems reached equilibrium after $250 \mathrm{~ns}$ when the RMSD values start fluctuating around about $0.3 \mathrm{~nm}$ and $0.45 \mathrm{~nm}$ for the backbone of protein_PB2 and around $0.1 \mathrm{~nm}$ for the inhibitor's heavy atoms in all cases. The snapshots collected from the last $100 \mathrm{~ns}$ of MD simulations were used to calculate the binding free energy through the MM-PBSA method. 


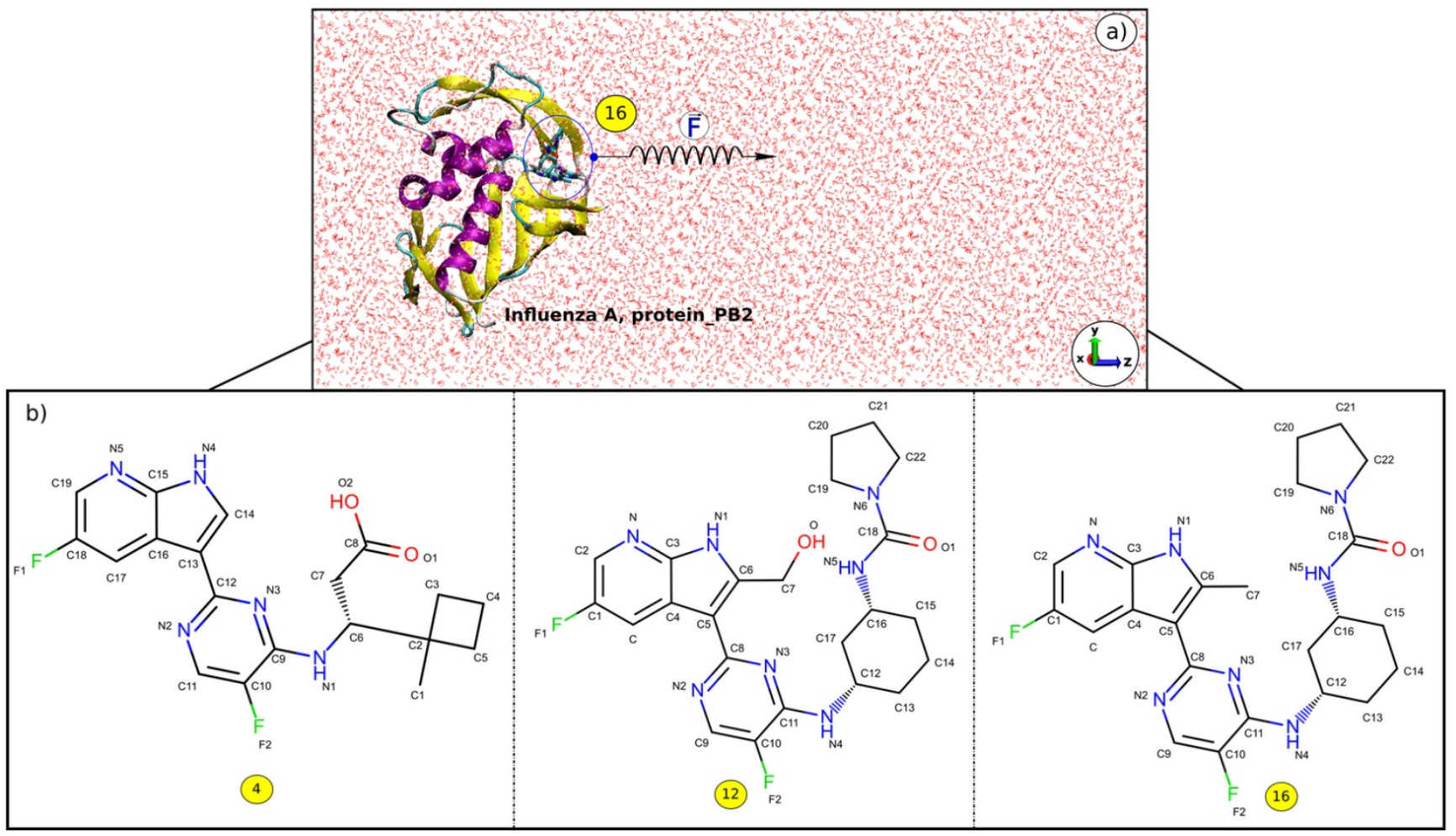

Figure 1. a) z-direction of the inhibitor (16) exiting the binding pocket of protein_PB2, and b) 2D structures of the inhibitors (4), (12), and (16).
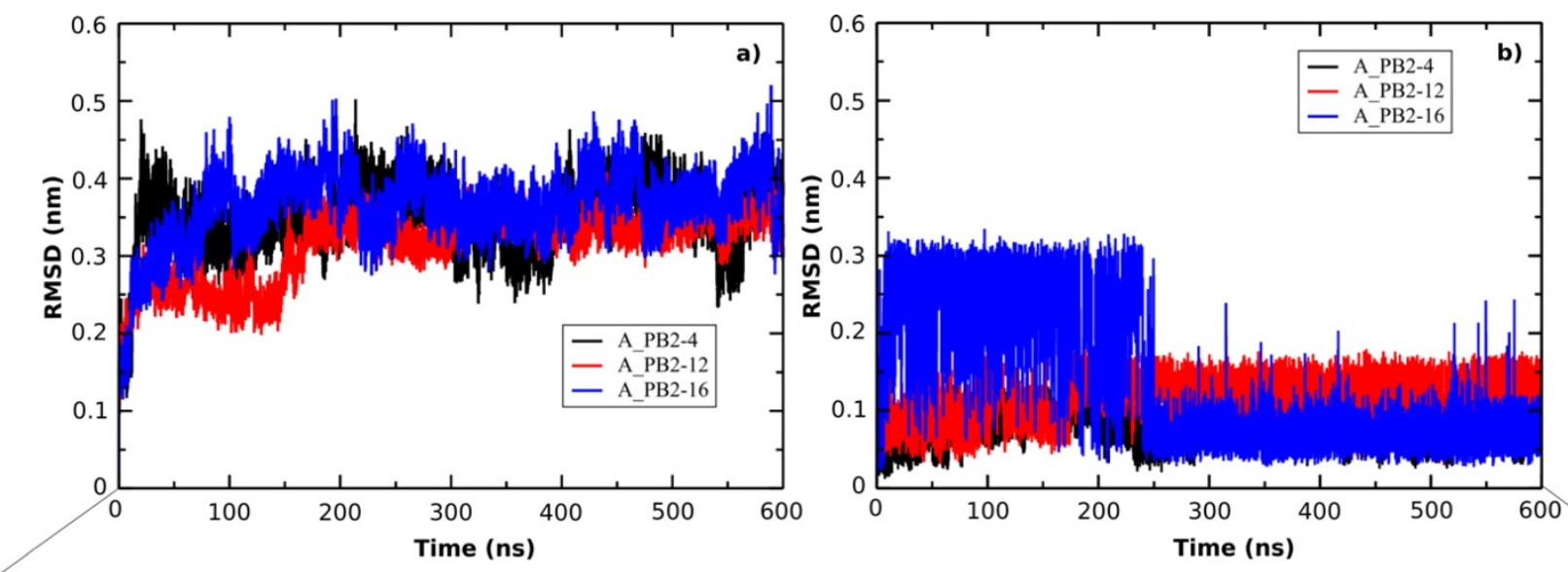

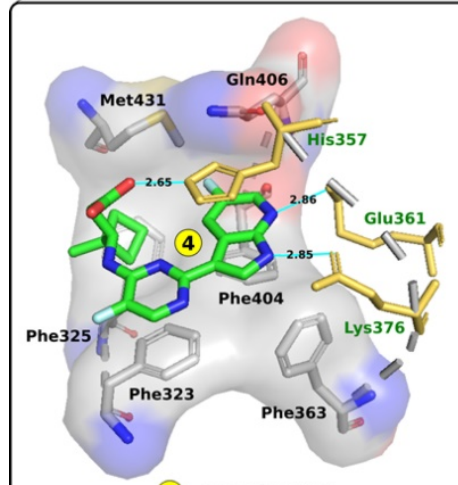

(4)- protein PB2

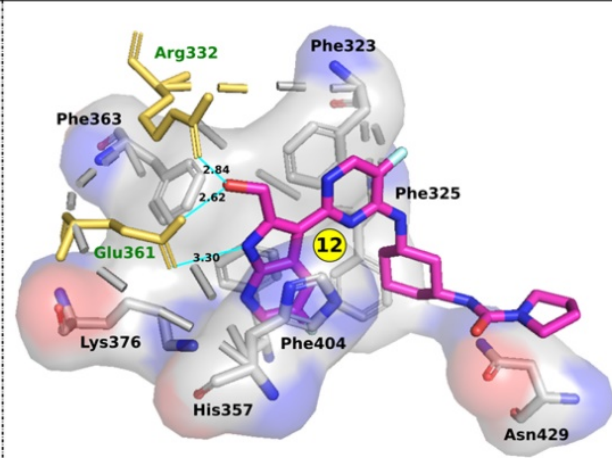

(12) - protein_PB2

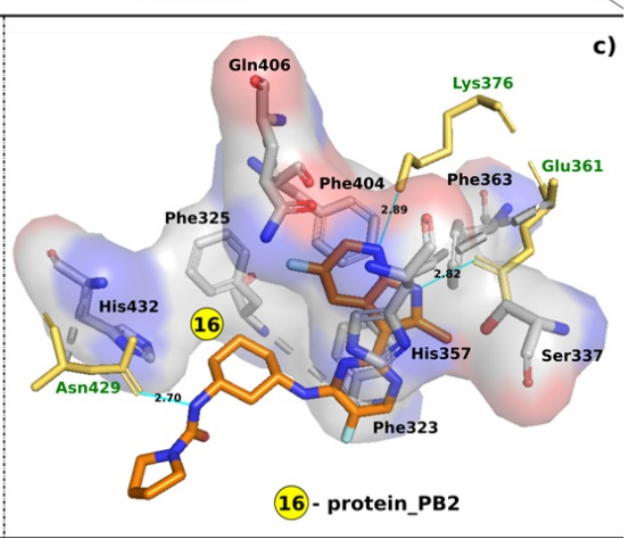

(16)- protein_PB2

Figure 2. RMSD time profiles for a) the backbone of protein PB2 in the three complexes and b) the heavy atoms of three inhibitors. c) the contact network between three inhibitors and protein_PB2. Residues shown in yellow form H-bonds (cyan lines) with the ligands. 

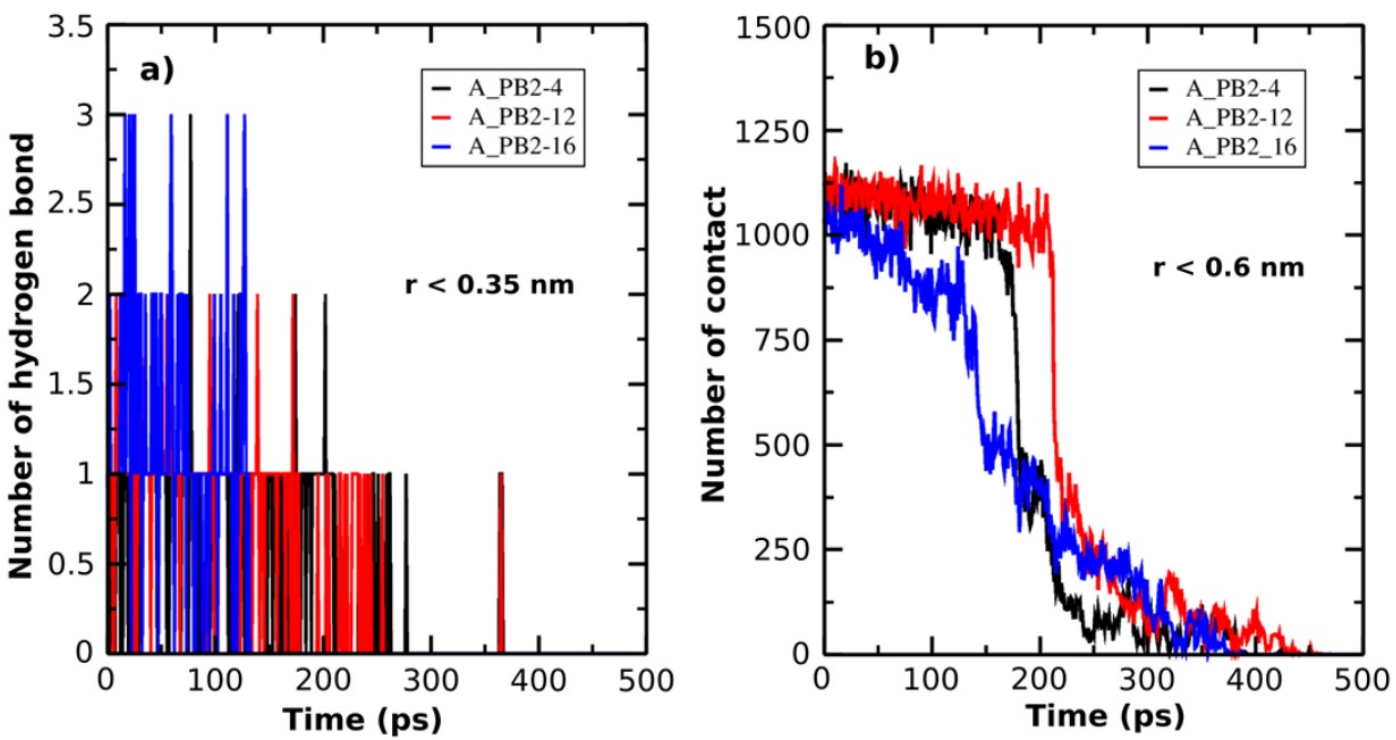

Figure 3. The number of $\mathrm{H}$-bonds (a) and the number of $\mathrm{NC}(\mathbf{b})$ formed between protein_PB2 and the inhibitors are presented as a function of SMD simulation time.

The contact network has an important role in stabilizing energetically favored inhibitors. Figure 2C displays the contact network between three inhibitors and protein_PB2. By analyzing the interfaces we found the following interactions:

- Both Glu361 and Lys376 form H-bonds with the inhibitors (4) and (16), while only Glu361 forms a H-bond with the inhibitor (12). The Glu361 residue seems to drive the interactions of the inhibitors-protein_PB2 systems. There are three residues forming $\mathrm{H}$-bonds with the inhibitor (4) (Glu361, Lys376, and His357) and the inhibitor (16) (Glu361, Lys376, and Asn429), while only two residues (Glu361 and Arg332) establish H-bonds with the inhibitor (12).

- Most of the H-bonds formed at the interfaces of the three complexes involve side chains of charged (Arg332, His357, Glu361, Lys376) residues, with Asn429 being the only neutral residue whose side chain forms $\mathrm{H}$-bonds with one of the compounds (16). The polar interaction energy can make a large contribution in estimating the binding affinity between the inhibitors and protein_PB2.

The H-bond between the inhibitors and protein_PB2 has an important role in the binding affinity of the complexes. Therefore, the average $\mathrm{H}$-bond occupancies (during the last $100 \mathrm{~ns}$ of the MD simulations) were also calculated to determine the contribution of each residue at the interfaces in each complex. The results indicate that the Phe323, Phe325, His357, Glu361, Phe363, Lys376, and Phe404 residues are involved in the formation of a H-bond network in the three complexes (Table 1). Most of the residues forming the contact network with three inhibitors are the Phe aromatic residues. That means the Phe residues can have a key role in interactions with the inhibitors and lead to the change of the binding affinity of the inhibitors for protein_PB2.

Table 1. Average occupancies of $\mathrm{H}$-bonds between the inhibitors and protein_PB2 in the three A_PB2-4, A_PB2-12, and A_PB2-16 complexes, determined from the last 100 ns of the MD simulations

\begin{tabular}{llll}
\hline Residue & Inhibitor (4) & Inhibitor (12) & Inhibitor (16) \\
\hline Phe323 (O) & $0.1873(\mathrm{~N} 4)$ & $0.0055(\mathrm{~N} 1)$ & $0.0044(\mathrm{~F} 2)$ \\
Phe325 (O) & $0.0431(\mathrm{~N} 4)$ & $0.1101(\mathrm{~F} 2)$ & $0.0112(\mathrm{~N} 5)$ \\
Arg332 (N) & & $0.4688(\mathrm{~N} 2, \mathrm{~F} 1, \mathrm{O})$ & \\
Ser337 (O) & & & $0.0019(\mathrm{~N})$ \\
His357 (N) & $0.6012(\mathrm{O} 1, \mathrm{O} 2)$ & $0.2155(\mathrm{~N} 2, \mathrm{O}, \mathrm{F} 1, \mathrm{~F} 2)$ & $0.0377(\mathrm{O} 1, \mathrm{~F} 2)$ \\
Glu361 (O) & $0.5202(\mathrm{~N} 5)$ & $0.8033(\mathrm{~N} 1, \mathrm{O})$ & $0.5010(\mathrm{~N} 1)$ \\
Phe363(O) & $0.0323(\mathrm{~N} 4)$ & $0.0795(\mathrm{~N} 1)$ & $0.2188(\mathrm{~N} 1)$ \\
Lys376 (N) & $0.4432(\mathrm{~N} 4)$ & $0.1113(\mathrm{~N}, \mathrm{O})$ & $0.6212(\mathrm{~N})$ \\
Phe404 (O) & $0.2261(\mathrm{~F} 1)$ & $0.2278(\mathrm{O})$ & $0.0220(\mathrm{~N})$ \\
Gln406 (N) & $0.0110(\mathrm{~N} 5)$ & & $0.0060(\mathrm{~N}, \mathrm{~N} 2, \mathrm{~F} 1, \mathrm{~F} 2)$ \\
Asn429 (N) & & $0.2032(\mathrm{~N} 6, \mathrm{O} 1, \mathrm{~F} 1)$ & $0.5721(\mathrm{~F} 1, \mathrm{~N} 5)$ \\
Met431 (O) & $0.0032(\mathrm{~N} 4)$ & & \\
His432 (N) & & & $0.0731(\mathrm{O} 1)$
\end{tabular}

Additionally, in order to describe the unbinding process of the inhibitor-protein_PB2 complexes, the H-bond $(\mathrm{r}<0.35 \mathrm{~nm})$ and the NC $(\mathrm{r}<0.6 \mathrm{~nm})$ are determined as a function of simulation time (Figure 3A \& B). At the bound state, there are three H-bonds formed between inhibitors (4) and (16) and protein_PB2, while there are only $2 \mathrm{H}$-bonds between inhibitor (12) and protein_PB2. At the unbound state, the number of $\mathrm{H}$-bonds decreases to 0 for all three complexes. Likewise, the NC value also helps follow the unbinding process of the inhibitor-protein_PB2 complexes. There are roughly 1125 NCs formed between the three inhibitors and protein_PB2 at the bound state, which decrease to 0 NCs after 400 ps for inhibitor (4), after 425 ps for inhibitor (16) and after 450 ps for inhibitor (12) at the unbound state. 
Although the NC and the number of $\mathrm{H}$-bonds of the A_PB2-16 complex are greater than those of the A_PB2-4 and A_PB2-12 complexes, the NC and the number of $\mathrm{H}$-bonds of the A_PB2-16 complex reach 0 faster than those of the A_PB2-4 and A_PB2-12 complexes.

\section{Binding affinity between the inhibitors and protein_PB2}

Binding affinity is widely used to evaluate and rank order strength of biomolecular interactions in biological systems. In this research, to make a full understanding of the binding mechanism of these inhibitors to protein_PB2, we estimated the binding affinity of the azaindole (4\&16) and hydroxymethyl azaindole (12) to protein_PB2.

The SMD is used as a method to study the unbinding process of small molecules (the inhibitors) from a large molecule (protein_PB2) and is capable of rank the compounds binding a same target protein according to their relative binding affinities [75]. The pulling force profile is started as a function of time (shown in Figure 4A). The $\mathrm{F}_{\max }$ has an important role to indicate the dissociation between protein_PB2 and the inhibitors. Here the pulling force profile is able to
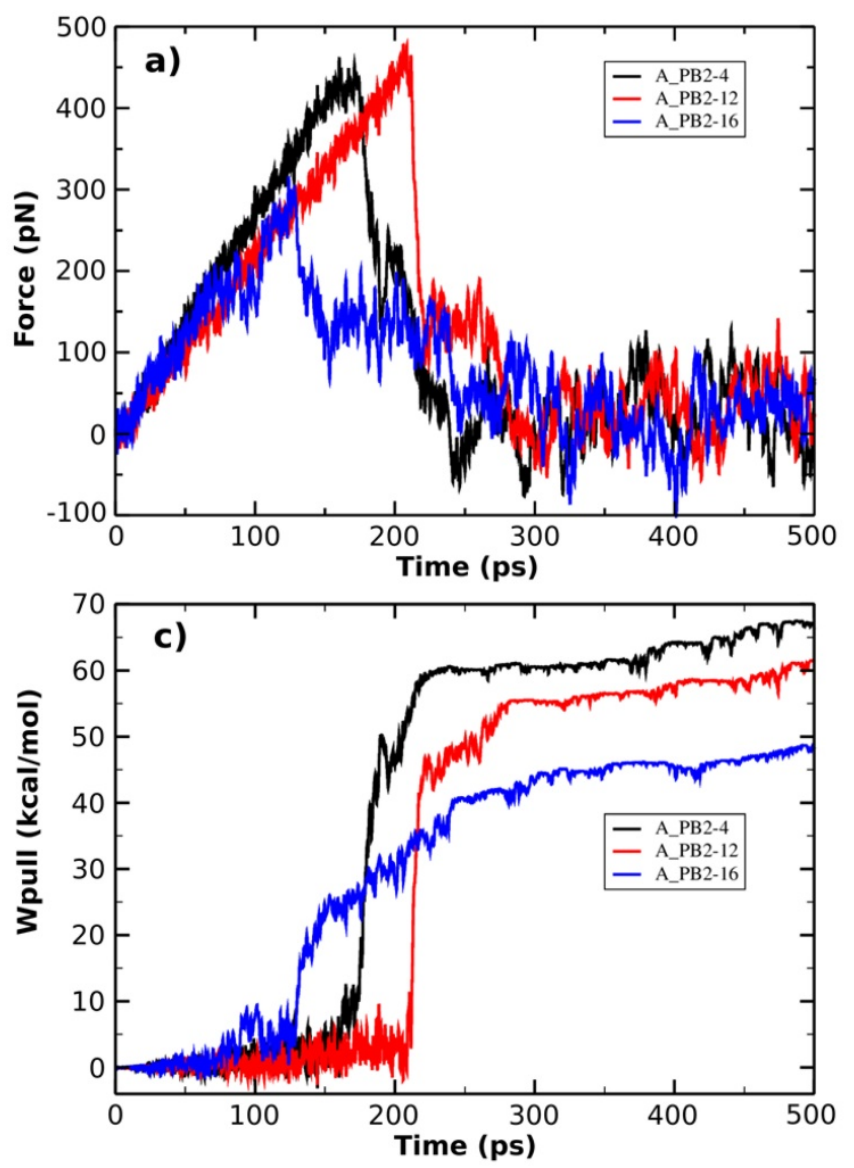

show the division of two consecutive stages: During the first stage, the pulling force continuously increased until the inhibitors started to dissociate from protein_PB2, and the external force reached the $\mathrm{F}_{\max }$ value when the $\mathrm{H}$-bonds are broken. During the second stage, the pulling force started to decrease as the inhibitors are exiting the binding pocket of protein_PB2. In more detail, the largest pulling force of the A_PB2-12 complex ( $\left.\mathrm{F}_{\max }=477.50 \mathrm{pN}, t=220 \mathrm{ps}\right)$ is larger than those of the A_PB2-4 complex $\left(\mathrm{F}_{\max }=\right.$ $462.42 \mathrm{pN}, t=170 \mathrm{ps})$ and the A_PB2-16 complex ( $\mathrm{F}_{\max }$ $=315.86 \mathrm{pN}, t=125 \mathrm{ps})$, respectively. Overall, the variation of pulling force profiles among the inhibitor-protein_PB2 complexes could be attributed to the binding site of protein_PB2. Moreover, the evolution of the steering force during the inhibitor displacement first showed a linear behavior which then became nonlinear before the $F_{\max }$ value was reached (seen from Figure 4B). At this point, the inhibitor is still located in the binding pocket. After obtaining the $F_{\max }$ value, the force value decreased steeply and fluctuated around zero value (beginning at $2.25 \mathrm{~nm}$ ), when the inhibitor detached from the protein_PB2 along the pulling direction.

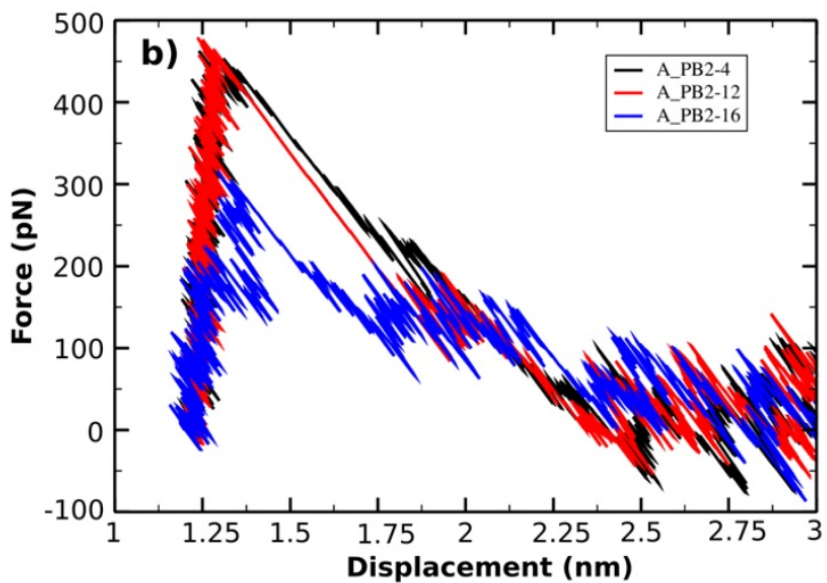

Figure 4. (a) Force vs time and (b) force vs displacement profiles. (c) Pulling work-time profile. 
Table 2. Binding affinity values of three inhibitors for protein_PB2, estimated from the MM-PBSA method and SMD simulations

\begin{tabular}{lllllllll}
\hline & $\Delta \mathrm{E}_{\text {elec }}(\mathrm{kcal} / \mathrm{mol})$ & $\Delta \mathrm{E}_{\text {vdw }}(\mathrm{kcal} / \mathrm{mol})$ & $\Delta \mathrm{G}_{\text {sur }}(\mathrm{kcal} / \mathrm{mol})$ & $\Delta \mathrm{G}_{\text {pв }}(\mathrm{kcal} / \mathrm{mol})$ & $-\mathrm{T} \Delta \mathrm{S}(\mathrm{kcal} / \mathrm{mol})$ & $\Delta \mathrm{G}_{\text {bind }}(\mathrm{kcal} / \mathrm{mol})$ & $\mathbf{F}_{\max }(\mathrm{pN})$ & $\mathbf{W}_{\text {pull }}(\mathrm{kcal} / \mathrm{mol})$ \\
\hline$(4)$ & $-7.63 \pm 1.77$ & $-2.17 \pm 0.25$ & $-6.95 \pm 1.05$ & $6.19 \pm 1.31$ & $0.52 \pm 0.02$ & $-10.04 \pm 1.63$ & $462.42 \pm 47.12$ & $77.13 \pm 8.25$ \\
$(12)$ & $-16.43 \pm 3.15$ & $-3.60 \pm 0.11$ & $-6.77 \pm 2.02$ & $6.74 \pm 1.73$ & $7.36 \pm 1.24$ & $-12.70 \pm 1.41$ & $477.50 \pm 51.61$ & $72.04 \pm 7.77$ \\
$(16)$ & $-7.71 \pm 1.14$ & $-1.86 \pm 0.05$ & $-4.41 \pm 0.93$ & $7.05 \pm 1.79$ & $0.49 \pm 0.02$ & $-6.44 \pm 1.12$ & $315.86 \pm 39.32$ & $55.12 \pm 6.75$ \\
\hline
\end{tabular}

The non-equilibrium pulling work $\left(\mathrm{W}_{\text {pull }}\right)$ is also used to predict the relative binding affinity of protein_PB2-inhibitor systems (eq. 2). As seen from Figure $4 C$, the $W_{\text {pull }}$ rapidly increased as the pulling force does, until the inhibitors come out from the binding pocket of protein_PB2. It reached a stable value when the inhibitors lost their non-bonded contacts with protein_PB2 (corresponding to 50 $\mathrm{kcal} / \mathrm{mol}$ for (16), $60 \mathrm{kcal} / \mathrm{mol}$ for (12) and 65 $\mathrm{kcal} / \mathrm{mol}$ for (4)). However, note that small fluctuations occur, which can be neglected. All three systems reach a stable state after 250 ps.

In this work, the MM-PBSA method is also used to estimate the binding free energies and makes possible to indicate the contribution of each energy component to the inhibitor's potency. As seen in Table 2, the contribution of different energy components to the $\Delta \mathrm{G}_{\text {bind }}$ indicates that the electrostatic energy $\left(\Delta \mathrm{E}_{\text {elec }}\right)$ has a more important role than the vdW energy $\left(\Delta \mathrm{E}_{\mathrm{vdW}}\right)$. The changes in the nonpolar solvation energy $\left(\Delta \mathrm{G}_{\text {sur }}\right)$ values significantly contributed to the difference of the $\Delta \mathrm{G}_{\text {bind }}$ among the complexes. The entropy $(-\mathrm{T} \Delta \mathrm{S})$ of the A_PB2-12 complex is larger than those of the A_PB2-4 and A_PB2-16 complexes. The loss of polar solvation energy $\left(\Delta \mathrm{G}_{\mathrm{PB}}\right)$ is compensated by the remaining components of the $\Delta G_{\text {bind }}$ in these systems.

Specifically, the $\Delta \mathrm{E}_{\text {elec }}$ obtained from the complex formation compensates the loss in $\Delta \mathrm{G}_{\mathrm{PB}}$. Here, the $\Delta \mathrm{E}_{\text {elec }}$ of the A_PB2-12 complex $(-16.43 \mathrm{kcal} / \mathrm{mol})$ is more negative than those of both remaining complexes $(-7.63 \mathrm{kcal} / \mathrm{mol}$ for the A_PB2-4 complex, and $-7.71 \mathrm{kcal} / \mathrm{mol}$ for the A_PB2-16 complex). The $\Delta \mathrm{G}_{\mathrm{vdW}}$ values of the three complexes (ranged from -1.86 to $-3.60 \mathrm{kcal} / \mathrm{mol}$ ) do not lead to the difference of their $\Delta \mathrm{G}_{\text {bind }}$ values. Conversely, the $\Delta \mathrm{G}_{\text {sur }}$ values of these complexes significantly contribute to the difference of their $\Delta \mathrm{G}_{\mathrm{bind}}$ values (ranged from -6.95 to $-4.41 \mathrm{kcal} / \mathrm{mol})$. The entropy contribution $(-\mathrm{T} \Delta \mathrm{S})$ of the A_PB2-12 complex $(7.36 \mathrm{kcal} / \mathrm{mol})$ is greater than those of the A_PB2-4 and A_PB2-16 complexes $(0.52$ $\mathrm{kcal} / \mathrm{mol}$ for the A_PB2-4 complex, and $0.49 \mathrm{kcal} / \mathrm{mol}$ for the A_PB2-16 complex). Clearly, the $\mathrm{OH}$ group of inhibitor (12) is not only yielded to a more negative value of electrostatic energy but also contributed to making a fairly large entropic energy. Here, the $-\mathrm{T} \Delta \mathrm{S}$ value of the A_PB2-12 complex contributed appreciably to the change of the binding free energy while this energy component has a negligible impact on the binding free energy to two remaining complexes. Finally, the $\Delta \mathrm{G}_{\text {bind }}$ of the A_PB2-12 complex $(-12.70 \mathrm{kcal} / \mathrm{mol})$ is lower than that of both remaining complexes $(-10.04 \mathrm{kcal} / \mathrm{mol}$ for the A_PB2-4 complex, and $-6.44 \mathrm{kcal} / \mathrm{mol}$ for the A_PB2-16 complex). The results indicate that the affinity of inhibitor (12) bound for protein_PB2 is stronger than that of inhibitors (4) and (16). Moreover, our calculations reveal that the $F_{\max }$ of three complexes is in good agreement with the $\Delta \mathrm{G}_{\text {bind }}$ value, while the $W_{\text {pull }}$ value has a small difference between A_PB2-4 and A_PB2-12. In short, the inhibitor (12) has the potential to be further developed as anti-influenza agents in the treatment of influenza A.

\section{Concluding Remarks}

In the present theoretical study, we applied the SMD and MM-PBSA methods to predict the binding affinity of three inhibitors for protein_PB2. A number of interesting results emerged from our work, which can be summarized as follows:

- The results from the MM-PBSA method showed that the electrostatics $\left(\Delta \mathrm{E}_{\text {elec }}\right)$ interaction plays a more important role than the van der Waals $\left(\Delta \mathrm{E}_{\mathrm{vdW}}\right)$ component in contributing to the binding free energy value of all three complexes. Additionally, the entropy (-T $\Delta S$ ) of the A_PB2-12 complex has a large detrimental impact on the binding free energy while it makes no significant contribution to the binding free energies of the A_PB2-4 and A_PB2-16 complexes.

- The $F_{\max }$ value of three complexes is in agreement with the $\Delta \mathrm{G}_{\text {bind }}$ value, while the $\mathrm{W}_{\text {pull }}$ value a small difference between the A_PB2-4 and A_PB2-12 complexes was observed. The binding affinities showed that the affinity of inhibitor (12) for protein_PB2 is stronger than that of inhibitors (4) and (16).

\section{Supplementary Material}

Supplementary parameterization scheme. http://www.medsci.org/v17p2031s1.pdf

\section{Acknowledgements}

We sincerely thank Prof. Mai Suan Li from the Institute of Physics, Polish Academy of Science, Poland; for supporting and valuable comments. This research was funded by the Department of Science and Technology - Ho Chi Minh City (HCMC - DOST), and the Institute for Computational Science and 
Technology (ICST) at Ho Chi Minh City, Vietnam under Contract No.14/2018/HĐ-KHCNTT. The computing resources were provided by the Institute for Computational Science and Technology at Ho Chi Minh City, Vietnam.

\section{Author Contributions}

$\mathrm{HN}$ conceived the experiment. TP and $\mathrm{HN}$ conducted the experiment. TP, HLN, TP-T and HN analyzed the results. HN wrote the paper. All authors reviewed the manuscript.

\section{Competing Interests}

The authors have declared that no competing interest exists.

\section{References}

1. Imai M, Watanabe T, Hatta M, Das SC, Ozawa M, Shinya K, Zhong G, Hanson A, Katsura H, Watanabe S, Li C, Kawakami E, Yamada S, Kiso M, Suzuki Y, Maher EA, Neumann G, Kawaoka Y. Experimental adaptation of an influenza H5 HA confers respiratory droplet transmission to a reassortant H5 HA/H1N1 virus in ferrets. Nature. 2012; 486:420-428.

2. Herfst S, Schrauwen EJ, Linster M, Chutinimitkul S, de Wit E, Munster VJ, Sorrell EM, Bestebroer TM, Burke DF, Smith DJ, Rimmelzwaan GF, Osterhaus $\mathrm{AD}$, Fouchier RA. Airborne transmission of influenza A/H5N1 virus between ferrets. Science. 2012; 336:1534-1541.

3. Taubenberger JK, Reid AH, Krafft AE, Bijwaard KE, Fanning TG. Initial genetic characterization of the 1918 "Spanish" influenza virus. Science. 1997; 275:1793-1796.

4. Garten RJ, Davis CT, Russell CA, Shu B, Lindstrom S, Balish A, Sessions WM, Xu X, Skepner E, Deyde V, Okomo-Adhiambo M, Gubareva L, Barnes J, Smith CB, Emery SL, Hillman MJ, Rivailler P, Smagala J, de Graaf M, Burke DF, Fouchier RA, Pappas C, Alpuche-Aranda CM, López-Gatell H, Olivera H, López I, Myers CA, Faix D,PJ Blair, Yu C, Keene KM, Dotson Jr PD, Boxrud D, Sambol AR, Abid SH, St George K, Bannerman T, Moore AL, Stringer DJ, Blevins P, Demmler-Harrison GJ, Ginsberg M, Kriner P, Waterman S, Smole S, Guevara HF, Belongia EA, Clark PA, Beatrice ST, Donis R, Katz J, Finelli L, Bridges CB, Shaw M, Jernigan DB, Uyeki TM, Smith DJ, Klimov AI, Cox NJ. Antigenic and genetic characteristics of swineorigin, A (H1N1) influenza viruses circulating in humans. Science. 2009; 325:197-201.

5. Mehle A, Doudna JA. Adaptive strategies of the influenza virus polymerase for replication in humans. Proc Natl Acad Sci U S A. 2009; 106:21312-21316.

6. Demicheli V, Rivetti D, Deeks JJ, Jefferson TO. Vaccines for preventing influenza in healthy adults. Cochrane Database Syst Rev. 2004: 7:CD001269.

7. Patriarca PA, Weber JA, Meissner MK, Stricof RL, Dateno B, Braun JE, Arden $\mathrm{NH}$, Kendal AP. Use of influenza vaccine in nursing homes. J Am Geriatr Soc. 1985; 33:463-466

8. Nichol KL, Wuorenma J, von Sternberg T. Benefits of influenza vaccination for low-, intermediate-, and high-risk senior citizens. Arch Intern Med. 1998; 158:1769-1779.

9. Glezen WP, Decker M, Perrotta DM. Survey of underlying conditions of persons hospitalized with acute respiratory disease during influenza epidemics in Houston, 1978-1981. Am Rev Respir Dis. 1987; 136:550-555.

10. Baughman BM, Jake Slavish P, DuBois RM, Boyd VA, White SW, Webb TR. Identification of influenza endonuclease inhibitors using a novel fluorescence polarization assay. ACS Chem Biol. 2012; 7:526-534.

11. Judith MF, Nicolle M, Hui T, John S, Anice CL. Influenza virus reassortment is enhanced by semi-infectious particle but can be suppresses by defective interfering particles. PLoS Pathog. 2015; 11: e1005204.

12. Christopher BB. Biological activities of "noninfectious" influenza A virus particles. Future Virol. 2014; 9: 41-51.

13. Wiley D, Skehel J. The structure and function of the Hemagglutinin membrane glycoprotein of influenza virus. Annu Rev Biochem. 1987; 56:365-394.

14. Skehel J, Wiley D. Receptor binding and membrane fusion in virus entry: The Influenza Hemagglutinin. Annu Rev Biochem. 2000; 69:531-569.

15. Colman P, Varghese J, Laver W. Structure of the catalytic and antigenic sites in influenza virus neuraminidase. Nature. 1983; 303:41-44.

16. Smith BJ, McKimm-Breshkin JL, McDonald M, Fernley RT, Varghese JN, Colman PM. Structural studies of the resistance of influenza virus neuraminidase to inhibitors. J Med Chem. 2002; 45-2207-2212.

17. Nguyen H, Tran T, Fukunishi Y, Higo J, Nakamura H, Le L. Computational study of drug binding affinity to influenza A Neuraminidase using smooth reaction path generation (SRPG) method. J Chem Inf Model. 2015; 55:1936-1943.
18. Nguyen $\mathrm{H}$, Le L. Steered molecular dynamics approach for promising drugs for influenza A virus targeting M2 channel proteins. Eur Biophys J. 2015; 44(6), 447-455.

19. Nguyen HV, Nguyen HT, Le LT. Investigation of the free energy profiles of Amantadine and Rimantadine in the AM2 binding pocket. Eur Biophys J. 2016; 45:63-70.

20. Hayden F. Developing new antiviral agents for influenza treatment: what does the future hold? Clin Infect Dis. 2009; 48(Suppl 1):S3-S13.

21. De Clercq E, Field HJ. Antiviral Chemistry \& Chemotherapy's current antiviral agents FactFile (2nd edition): RNA viruses. Antivir Chem and Chemother. 2008; 19:63-74

22. Lüscher-Mattli M. Influenza chemotherapy: A review of the present state of art and of new drugs in development. Arch Virol. 2000; 145:2233-2248.

23. Moscona A. Medical management of influenza infection. Annu Rev Med. 2008; 59:397-413.

24. Wilson JC, von Itzstein M. Recent strategies in the search for new anti-influenza therapies. Curr Drug Targets. 2003; 4:389-408.

25. Beigel J, Bray M. Current and future antiviral therapy of severe seasonal and avian influenza. Antiviral Res. 2008; 78:91-102.

26. Leyssen P, De Clercq E, Neyts J. Molecular strategies to inhibit the replication of RNA viruses. Antiviral Res. 2008; 78:9-25.

27. Boltz DA, Aldridge JR Jr, Webster RG, Govorkova EA. Drugs in development for influenza. Drugs. 2010; 70:1349-1362.

28. Das K, Aramini JM, Ma LC, Krug RM, Arnold E. Structures of influenza A proteins and insights into antiviral drug targets. Nat Struct Mol Biol. 2010; 17:530-538.

29. Hooker L, Strong R, Adams R, Handa B, Merrett JH, Martin JA, Klumpp K. A sensitive, single-tube assay to measure the enzymatic activities of influenza RNA polymerase and other poly(A) polymerases: application to kinetic and inhibitor analysis. Nucleic Acids Res. 2001; 29:2691-2698.

30. Honda A, Ueda $K$, Nagata $K$, Ishihama A. Identification of the RNA polymerase-binding site on genome RNA of influenza virus. J Biochem. 1987; 102:1241-1249.

31. Noda $T$, Sagara $H$, Yen A, Takada A, Kida $H$, Cheng $R H$, Kawaoka $Y$. Architecture of ribonucleoprotein complexes in influenza A virus particles. Nature. 2006; 439:490-492.

32. Coloma R, Valpuesta JM, Arranz R, Carrascosa JR, Ortín J, Martín-Benito J. The structure of a biologically active influenza virus ribonucleoprotein complex. PLoS Pathog. 2009; 5:e1000491.

33. Ng AK, Zhang H, Tan K, Li Z, Liu JH, Chan PK, L SM, Chan WY, Au SW, Joachimiak A, Walz T, Wang JH, Shaw PC. Structure of the influenza virus A H5N1 nucleoprotein: implications for RNA binding, oligomerization, and vaccine design. FASEB J. 2008; 22:3638-3647.

34. Ye Q, Krug RM, Tao YJ. The mechanism by which influenza A virus nucleoprotein forms oligomers and binds RNA. Nature. 2006; 444:1078-1082.

35. Plotch SJ, Bouloy M, Ulmanen I, Krug RM. A unique cap (m7GpppXm)-dependent influenza virion endonuclease cleaves capped RNAs to generate the primers that initiate viral RNA transcription. Cell. 1981; 23.847-858

36. Dias A, Bouvier D, Crépin T, McCarthy AA, Hart DJ, Baudin F, Cusack S, Ruigrok RW. The cap-natching endonuclease of influenza virus polymerase resides in the PA subunit Nature 2009:458.914-918.

37. Yuan P, Bartlam M, Lou Z, Chen S, Zhou J, He X, Lv Z, Ge R, Li X, Deng T, Fodor E, Rao Z, Liu Y. Crystal structure of an avian influenza polymerase $\mathrm{PA}(\mathrm{N})$ reveals an endonuclease active site. Nature; 2009; 458:909-913.

38. Guilligay D, Tarendeau F, Resa-Infante P, Coloma R, Crepin T, Sehr P, Lewis J, Ruigrok RW, Ortin J, Hart DJ, Cusack S. The structural basis for cap binding by influenza virus polymerase subunit PB2. Nat Struct Mol Biol. 2008; 15:500-506.

39. Datta K, Wolkerstorfer A, Szolar OH, Cusack S, Klumpp K. Characterization of PA-N terminal domain of Influenza A polymerase reveals sequence specific RNA cleavage. Nucleic Acids Res. 2013; 41:8289-8299.

40. Blaas D, Patzelt E, Keuchler E. Identification of the cap binding protein of influenza virus. Nucleic Acids Res. 1982; 10:4803-4812.

41. Shi L, Galarza JM, Summers DF. Recombinant-baculovirus-expressed PB2 subunit of the influenza A virus RNA polymerase binds cap groups as an isolated subunit. Virus Res. 1996; 42:1-9.

42. Ulmanen I, Broni BA, Krug RM. Role of two of the influenza virus core P proteins in recognizing cap 1 structures $(\mathrm{m} 7 \mathrm{GpppNm})$ on RNAs and in initiating viral RNA transcription. Proc Natl Acad Sci U S A. 1981; 78:7355-7359.

43. Perales B, de la Luna S, Palacios I, Ortín J. Mutational analysis identifies functional domains in the influenza A virus PB2 polymerase subunit. J Virol. 1996; 70(3), 1678-1686.

44. Ba'rcena J, Ochoa M, de la Luna S, Melero JA, Nieto A, Ortín J, Portela A. Monoclonal antibodies against influenza virus PB2 and NP polypeptides interfere with the initiation step of viral mRNA synthesis in vitro. J Virol. 1994; 68:6900-6909.

45. Blok V, Cianci C, Tibbles KW, Inglis SC, Krystal M, Digard P. Inhibition of the influenza virus RNA-dependent RNA polymerase by antisera directed against the carboxy-terminal region of the PB2 subunit. J Gen Virol. 1996; 77:1025-1033.

46. Masunaga K, Mizumoto K, Kato H, Ishihama A, Toyoda T. Molecular mapping of influenza virus RNA polymerase by site-specific antibodies. Virology. 1999; 256:130-141. 
47. Li ML, Rao P, Krug RM. The active sites of the influenza cap-dependent endonuclease are on different polymerase subunits. EMBO J. 2001; 20:2078-2086.

48. Cianci C, Tiley L, Krystal M. Differential activation of the influenza virus polymerase via template RNA binding. J Virol. 1995; 69:3995- 3999.

49. Hagen M, Chung TD, Butcher JA, Krystal M. Recombinant influenza virus polymerase: requirement of both $5^{\prime}$ and $3^{\prime}$ viral ends for endonuclease activity. J Virol. 1994; 68:1509-1515.

50. Nguyen H, Pham T, Nguyen HL, Phan T. Investigation of binding affinity between Prokaryotic protein (AHU-IHF) and DNAs: Steered molecular dynamics approach. Appl Biochem Biotechnol. 2018; 186:834-846.

51. Truong DT, Li MS. Probing the binding affinity by Jarzynski's non-equilibrium binding free energy and rupture time. J Phys Chem B. 2018; 122:4693-4699.

52. Nguyen H, Do N, Phan T, Pham T. Steered molecular dynamics for investigating the interaction between insulin receptor tyrosine kinase (IRK) and variants of protein tyrosine phosphatase 1B(PTP1B). Appl Biochem Biotechnol. 2018; 184:401-413.

53. Nguyen $H$, Nguyen $T$, Le L. Computational study of Glucose-6-phosphate-dehydrogennase deficiencies using molecular dynamics simulation. S Asian J Life Sci. 2016; 4:32-39.

54. Wang J, Morin P, Wang W, Kollman PA. Use of MM-PBSA in reproducing the binding free energies to HIV-1 RT of TIBO derivatives and predicting the binding mode to HIV-1 RT of efavirenz by docking and MM-PBSA. J Am Chem Soc. 2001; 123: 5221-5230.

55. Farmer LJ, Clark MP, Boyd MJ, Perola E, Jones SM, Tsai A, Jacobs MD, Bandarage UK, Ledeboer MW, Wang T, Deng H, Ledford B, Gu W, Duffy JP, Bethiel RS, Shannon D, Byrn RA, Leeman JR, Rijnbrand R, Bennett HB, O'Brien C, Memmott C, Nti-Addae K, Bennani YL, Charifson PS. Discovery of novel, orally bioavailable $\beta$-Amino acid azaindole inhibitors of influenza PB2. ACS Medical Chemistry Letters. 2017; 8:256-260.

56. Bandarage UK, Clark MP, Perola E, Gao H, Jacobs MD, Tsai A, Gillespie J, Kennedy JM, Maltais F, Ledeboer MW, Davies I, Gu W, Byrn RA, Nti Addae $\mathrm{K}$, Bennett H, Leeman JR, Jones SM, O'Brien C, Memmott C, Bennani Y, Charifson PS. Novel 2-Substituted 7-Azaindole and 7-Azaindazole Analogues as potential antiviral agents for the treatment of influenza. ACS Med Chem Lett. 2017; 8:261-265.

57. Zoete V, Cuendet MA, Grosdidier A, Michielin O. SwissParam, a fast force field generation tool for small organic molecules. J Comput Chem. 2011; 32:2359-2368. DOI: $10.1002 /$ jcc.21816.

58. Vanommeslaeghe K, Hatcher E, Acharya C, Kundu S, Zhong S, Shim J, Darian E, Guvench O, Lopes P, Vorobyov I, MacKerell Jr AD. CHARMM General Force Field (CGenFF): A force field for drug-like molecules compatible with the CHARMM all-atom additive biological force fields. J Comput Chem. 2010; 31:671-690.

59. Hess B, Kutzner C, van der Spoel D, Lindahl E. GROMACS 4: Algorithms for highly efficient, load-balanced, and scalable molecular simulation. J Chem Theory Comput. 2008; 4:435-447.

60. Mark P, Nilsson L. Structure and dynamics of the TIP3P, SPC, and SPC/E water models at 298 K. J Phys Chem A. 2001; 105:9954-9960.

61. Hess B, Bekker H, Berendsen HJC, Fraaije JGEM. LINCS: A linear constraint solver for molecular simulations. J Comput Chem. 1997; 18:1463-1472.

62. Darden T, York D, Pedersen L. Particle Mesh Ewald: An $N \log (N)$ method for Ewald sums in large systems. J Chem Phys. 1993; 98:10089-10092.

63. Hockney RW, Goel SP, Eastwood J. Quit high resolution computer models of plasma. J Comput Phys. 1974; 14:148-158.

64. Petrek M, Otyepka M, Banas P, Kosinova P, Koca1 J, Damborsky J. CAVER: A new tool to explore routes from protein clefts, pockets and cavities. BMC Bioinformatics. 2006; 7:316.

65. PyMOL: The PyMOL Molecular Graphics System, version 1.3; Schrödinger, LLC: Cambridge, MA, 2010.

66. Gibson CT, Carnally S, Roberts CJ. Attachment of carbon nanotubes to atomic force microscope probes. Ultramicroscopy. 2007; 107:1118-1122.

67. Baker NA, Sept D, Joseph S, Holst MJ, McCammon JA. Electrostatics of nanosystems: application to microtubules and the ribosome. Proc Natl Acad Sci U S A. 2001; 98:10037-10041.

68. Binnig G, Quate CF, Gerber Ch. Atomic force microscope. Phys Rev Lett. 1986; 56:930.

69. Sharp KA, Honig B. Electrostatic interactions in macromolecules: theory and applications. Annu Rev Biophys Bio. 1990; 19:301-332.

70. Baker NA, Sept D, Joseph S, Holst MJ, McCammon JA. Electrostatics of nanosystems: application to microtubules and the ribosome. Proc Natl Acad Sci USA. 2001; 98:10037-10041.

71. Shrake A, Rupley JA. Environment and exposure to solvent of protein atoms-lysozyme and insulin. J Mol Biol. 1973; 79:351-371.

72. Sitkoff D, Sharp KA, Honig B. Accurate calculation of hydration free energies using macroscopic solvent models. J Phys Chem. 1994; 97:1978-1988.

73. Duan L, Liu X, Zhang JZ. Interaction entropy: A new paradigm for highly efficient and reliable computation of protein-ligand binding free energy. J Am Chem Soc. 2016; 138:5722-5728.

74. Laskowski RA, Swindells MB. LigPlot+: multiple ligand-protein interaction diagrams for drug discovery. J Chem Inf Model. 2011; 51:2778-2786.

75. Do P-C, Lee EH, Le L. Steered molecular dynamics simulation in rational drug design. J Chem Inf Model. 2018; 58:1473-1482. 